\title{
Ice discharge error estimates using different cross-sectional area approaches: a case study for the Canadian High Arctic, 2016/17
}

\author{
PABLO SÁNCHEZ-GÁMEZ, ${ }^{1}$ FRANCISCO J. NAVARRO ${ }^{1}$ \\ ${ }^{1}$ Departamento de Matemática Aplicada a las TIC, ETSI Telecomunicación, Universidad Politécnica de Madrid, Av. \\ Complutense 30, 28040 Madrid, Spain \\ Correspondence: Pablo Sánchez-Gámez <pablo.sgamez@upm.es>
}

\begin{abstract}
We analyse the various error sources in the estimation of ice discharge through flux gates, distinguishing the cases with ice-thickness data available for glacier cross-sections or only along the centreline. For the latter, we analyse the performance of three U-shaped cross-sectional approaches. We apply this methodology to glaciers of the Canadian High Arctic. The velocity field is the main error source for small and medium-size glaciers (discharge $\left.<100 \mathrm{Mt} \mathrm{a}^{-1}\right)$ with low velocities $\left(<100 \mathrm{~m} \mathrm{a}^{-1}\right)$, while for large glaciers (discharge $>100 \mathrm{Mt} \mathrm{a}^{-1}$ ) with high velocities $\left(>100 \mathrm{~m} \mathrm{a}^{-1}\right.$ ) the error in crosssectional area dominates. Thinning/thickening between ice-thickness and velocity measurements should be considered, as it implies systematic errors up to $8 \%$ in our study. The U-shaped parabolic approach, which allows for an adjusted estimation when the ice-thickness measurement point is displaced from the glacier centreline, performs best, with small bias and admissible standard error. We observe an increase of ice discharge from the main glaciers (Trinity and Wykeham) of the Prince of Wales Icefield from 2015 to 2016, by 5 and $20 \%$, respectively, followed by a decrease in 2017, by 10 and $15 \%$, respectively. Belcher Glacier, of the Devon Ice Cap, maintains similar discharges during 2015-17.
\end{abstract}

KEYWORDS: Arctic glaciology, glacier discharge, ice dynamics, remote sensing

\section{INTRODUCTION}

Frontal ablation, that is, ice mass losses by calving, subaerial frontal melting and sublimation and subaqueous frontal melting (Cogley and others, 2011), is an important component of the mass balance of tidewater glaciers and marineterminating ice caps. It has been reported to account for up to $30-40 \%$ of the total ablation of some Arctic glacierised archipelagos and ice caps (Dowdeswell and others, 2002, 2008; Błaszczyk and others, 2009) and up to $50 \%$ in some ice caps in the Antarctic periphery (Osmanoğlu and others, 2014). Because of the difficulty of calculating the components of frontal ablation separately, it is usually approximated by the ice discharge through flux gates close to the calving fronts, calculated as the product of ice velocity and cross-sectional area (volumetric flux). If the considered flux gate is not close to the calving front, the surface mass balance between them should be taken into account (Andersen and others, 2015; McNabb and others, 2015). Neglecting this effect will in nearly all cases lead to an overestimation of the frontal ablation. For Alaskan glaciers, McNabb and others (2015) found an overestimate of $19 \%$ on average for individual glaciers ( $10 \%$ for the regional total). For Canadian Arctic glaciers the overestimate is expected to be larger, because of the strongly negative recent surface mass balance of this region (Gardner and others, 2011). Possible front position changes should also be taken into consideration (Burgess and Sharp, 2004; Burgess and others, 2005; Williamson and others, 2008; Van Wychen and others, 2016), though the terminus advance/retreat is in general expected to account for a smaller share of the frontal ablation estimates. For instance, McNabb and others (2015) indicated an overestimation of $13 \%$ ( $2 \%$ of the regional total) by neglecting advance/retreat of the terminus for Alaskan glaciers. This effect is more difficult to quantify for the Canadian Arctic glaciers due to the pulsating behaviour of many of them (Williamson and others, 2008; Van Wychen and others, 2016, 2017). Pulsating glaciers, as surging glaciers, show periods of speedup and slowdown. However, the velocity variability of pulsating glaciers is restricted to their lowermost terminal zone, which is grounded below sea level. Additional factors influencing frontal ablation estimates, such as cross-sectional ice-thickness variations and longterm thickness changes have been discussed, e.g. by McNabb and others (2015). The seasonality of the glacier velocity measurements can also have a noticeable impact on frontal ablation estimates, with seasonal velocity amplitudes averaging $\sim 50 \%$ of the peak velocity for Alaskan glaciers (McNabb and others, 2015) and $\sim 45 \%$ in Livingston Island, off the northwestern Antarctic Peninsula (Osmanoğlu and others, 2014). The changes for the Canadian Arctic glaciers seem to be more modest, with a seasonal variability of $\sim 10-20 \%$ of the average values (Van Wychen and others, 2012). The interannual variations of glacier velocity are also an important issue, particularly for the Canadian Arctic glaciers due to their pulsating nature. Estimates of total error in frontal ablation accounting for the various error sources described above are typically within $\sim 20-30 \%$. For instance, values of 24 and $25 \%$ have been given for some Alaskan glaciers by McNabb and others (2015) and Vijay and Braun (2017), respectively, while a value of $31 \%$ has been given by Van Wychen and others (2016) for the Canadian High Arctic.

In this paper, we will focus on analysing the errors in the ice discharge estimates through given flux gates, so we will 
refer to ice discharge rather than frontal ablation. A fundamental problem for estimating the ice discharge is that very often the cross-sectional area of tidewater glaciers is unknown. Normally, there is a lack of information regarding the thickness of glaciers. Typically, glacier thickness is only known along the central flowline, sometimes on the glacier's cross section and very rarely both of them are available for a specific glacier (Leuschen and others, 2010). This scarcity in ice-thickness data motivates the use of U-shaped cross-sectional profiles for ice discharge estimates when only icethickness data along the glacier flowline is available (Van Wychen and others, 2012). Inverse modelling is used when we count on little ice-thickness data, or no data at all (Farinotti and others, 2009). Observed thickness data can be assimilated into inverse methods (Osmanoğlu and others, 2013, 2014).

Different approaches have been taken in the literature to estimate the error in ice discharge through flux gates. However, most of them only provide upper and lower bounds of the error (Burgess and others, 2005; Van Wychen and others, 2012), rather than statistical estimates of the expected error with a certain degree of uncertainty. In this paper, we aim to contribute to fill this gap by analysing, using error propagation, the various error sources involved in the estimate of ice discharge, and to quantify their individual contributions to the total error in ice discharge.

When cross-sectional ice-thickness measurements are not available, ice-discharge estimates through given flux gates can be based on an increasingly complex approach, ranging from the so-called box-shaped approaches (Brown and others, 1982; Rignot and others, 2008; Williamson and others, 2008; Błaszczyk and others, 2009; Burgess and others, 2013) to those considering a varying cross-sectional depth (Van Wychen and others, 2012, 2014, 2015, 2016,
2017). The box-shaped approach shows a tendency to overestimate the ice discharge, so we will not use it in this paper. Various U-shaped approaches can be taken, and a detailed analysis of their performance, on the basis of the comparison of their results with those for a large set of observed cross-sectional areas, is lacking in the literature. Filling this gap is the second aim of the present paper.

The two above analyses will be based on ice discharge estimates for the Canadian High Arctic using ice-thickness data and remotely sensed glacier surface-velocity data from 2012-15 and 2016/17 respectively. This will provide, as a by-product of this paper, updated ice-discharge estimates for glaciers of the Canadian High Arctic during 2016/2017.

\section{STUDY SITE AND DATA}

The Queen Elizabeth Islands (Ellesmere, Axel Heiberg and Devon islands) are located in the Canadian Arctic, neighbouring the western coast of Greenland (Fig. 1a). This region is often referred to as Canadian High Arctic. The ice masses of Ellesmere Island contain one-third of the global volume of land ice outside Greenland and Antarctica (Radic and Hock, 2010) with a glacierised area in 2000 of ca. $104000 \mathrm{~km}^{2}$ (Sharp and others, 2014) while Devon Ice Cap covers $\sim 14000 \mathrm{~km}^{2}$ and is one of the largest ice caps in the Arctic (Dowdeswell and others, 2004). The dynamics of Canadian Arctic glaciers and ice caps have been extensively studied (Copland and others, 2003; Dowdeswell and others, 2004; Burgess and others, 2005; Williamson and others, 2008; Gardner and others, 2011; Van Wychen and others, 2012, 2014, 2015, 2016; Millan and others, 2017; Strozzi and others, 2017). Copland and others (2003) made an analysis on the surge-type glaciers in this region and later studies by Van Wychen and others (2016, 2017) developed a classification scheme into three

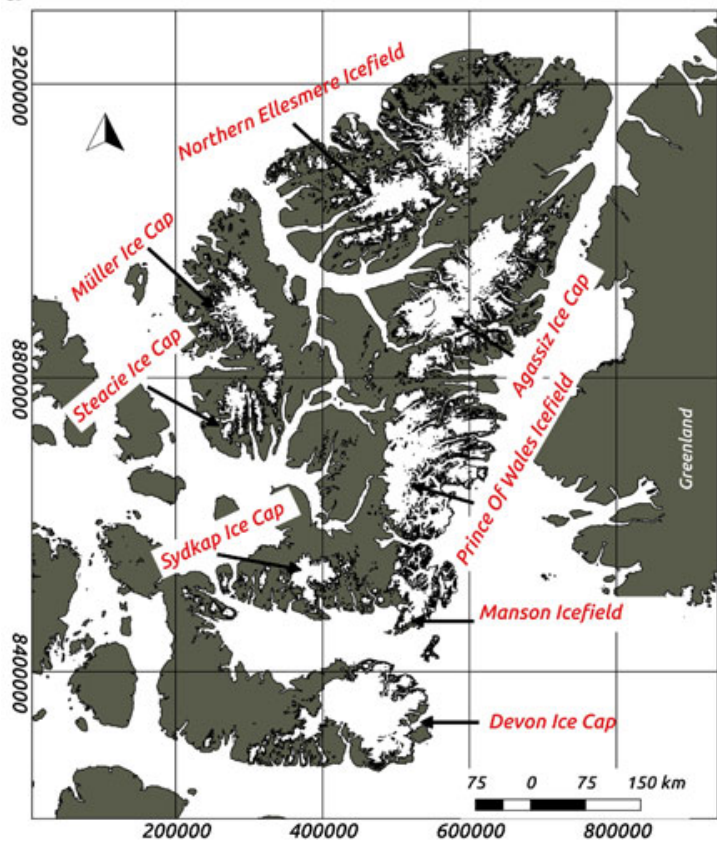

b

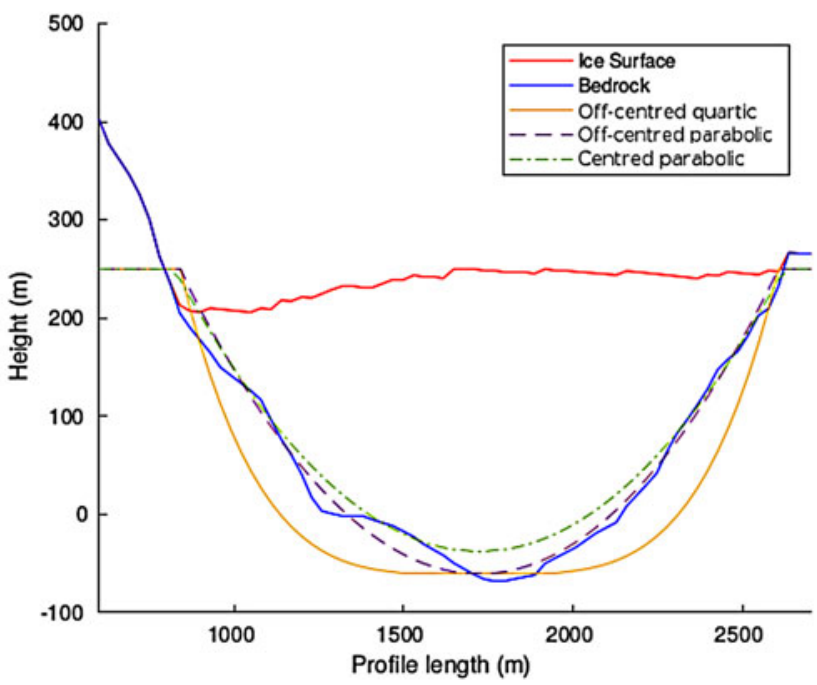

Fig. 1. (a) Main ice masses of Ellesmere, Axel Heiberg and Devon Islands, Canadian High Arctic (Wessel and Smith, 1996). The glacier outlines are from the Randolph Glacier Inventory (RGI) version 5.0 (Pfeffer and others, 2014). See more detail in Supplementary Materials figures S1, S2 and S3, and Table S1. (b) Cross-sectional profile approaches overlaid on a real glacier cross section. All maps in this paper use the Universal Transverse Mercator (UTM) projection of the zone 17 north, and the reference ellipsoid is WGS84. 
glacier types depending on their dynamics: surging, pulsing and consistent acceleration/deceleration. These investigations indicate that the glaciers of the Canadian High Arctic show marked differences in dynamic behaviour, and large spatial and temporal variabilities.

The datasets used in this study encompass synthetic aperture radar (SAR) images from the Sentinel-1 platform, Operation IceBridge airborne radar ice thickness (Leuschen and others, 2010; Gogineni, 2012) and the freely accessible Canadian DEM (CDEM) designed by Natural Resources Canada (NRCan) with a resolution of 0.75 and 3 arcsec in the southnorth and westeast directions, respectively (NRCAN, 2016). The DEM was used for geocoding and coregistering the imagery employed for the intensity offset tracking technique. ArcticDEM from WorldView satellite, from 2012 and 2014-15, was used for estimating local icethickness changes from surface-elevation changes, assuming no glacier-bed elevation change.

The surface velocities on the Canadian High Arctic were obtained from SAR Terrain Observation by Progressive Scans (TOPS) Interferometric Wide (IW) Level-1 Single Look Complex (SLC) images. These products provide a geo-referenced image (using accurate altitude and orbital information from the satellite), in slant-range geometry, processed in zero-Doppler (Geudtner and others, 2014). The image is normally composed of three sub-swaths with each sub-swath comprising normally nine consecutive bursts, which overlap in azimuth. Burst synchronisation is needed for interferometry and for accurate offset tracking (Holzner and Bamler, 2002). The resolution of Sentinel-1 SAR TOPS IW mode is of 5 and $20 \mathrm{~m}$ in the range and azimuth directions, respectively. The SAR images used in this study were acquired during the winter of the year 2016 (beginning of February until mid-March) and the winter of the following year (end of January to mid-March 2017). See more detail in Supplementary Materials Table S2.

The ice-thickness dataset lumps a wide variety of data regarding both acquisition dates and geographical distribution (Table 1). In particular, we count on transverse ice-thickness profiles for 23 glaciers, and 20 additional glaciers for which only along-flow, close to centreline ice-thickness profiles are available, totalling 43 studied glaciers in the area. Ice-thickness data were measured using the Multichannel Coherent RADAR Depth Sounder (MCoRDS) (Leuschen and others, 2010). Specifically, the dataset used in this study is the post-processed L2, which contains information about time, latitude, longitude, elevation, glacier surface and bed elevation, and ice thickness, the latter one with an estimated uncertainty of $\pm 10 \mathrm{~m}$ (Gogineni, 2012).

Table 1. Operation IceBridge airborne radar profiles used in this study. Cross means cross-sectional profiles and Long means longitudinal (along-flow, close to glacier centreline) profiles

\begin{tabular}{llr}
\hline Data location & \multicolumn{1}{c}{ Profile type } & \multicolumn{1}{c}{ Year } \\
\hline Prince of Wales Icefield & Cross(10)-Long(8) & $2012-14$ \\
Devon Ice Cap & Cross(8)-Long(6) & $2012-15$ \\
Northern Ellesmere Icefield & Cross(2)-Long(8) & 2014 \\
Agassiz Ice Cap & Long(8) & 2014 \\
Müller and Steacie Ice Caps & Long(2) & 2014 \\
Manson Icefield & Cross(2) & 2012 \\
Sydkap & Cross(1)-Long(1) & 2012 \\
& & \\
\hline
\end{tabular}

\section{METHODOLOGY}

We calculate the ice discharge using a flux-gate approach for two cases: (1) the cross-sectional depth profile is known (Vijay and Braun, 2017), and (2) the cross section is estimated using an approximation to the depth profile (Harbor, 1992; Cuffey and Paterson, 2010). For the latter case, we will use three different approaches, a centred parabola for which the ice thickness at the glacier centreline is assumed to be known, a centred parabola with ice thickness known at an off-centred point and a quartic function with ice thickness known at an off-centred point. The availability of airborne radar cross-sectional profiles for 23 Canadian High Arctic glaciers, which will be taken as reference, will allow us to compare the accuracy of the various cross-sectional area approaches.

\subsection{Ice discharge}

Ice discharge is calculated as mass flux per unit time across a given surface $S$ approximated per area bins as

$$
\phi=\int_{S} \rho \mathbf{v} \cdot \mathbf{d} \mathbf{S}=\sum_{i} \rho L_{i} H_{i} f v_{i} \cos \alpha_{i}
$$

where $\rho$ is ice density, $L_{i}$ and $H_{i}$ are respectively the width and thickness of an area bin, $f$ is the ratio of surface to depth-averaged velocity, $f \in[0.8,1]$ (Thomas and others, 2000; Cuffey and Paterson, 2010; Andersen and others, 2015), $v_{i}$ is the magnitude of surface velocity and $\alpha_{i}$ is the angle between the surface velocity vector and the direction normal to the local flux-gate for the bin under consideration. When airborne radar cross-sectional profiles are available, we define the bin widths and orientations as given between consecutive radar-measured points; when no cross-sectional airborne radar profiles are available, we use bins of fixed width and thickness estimated from the corresponding cross-sectional profile approach, and the velocity vector orientations are calculated with respect to the vector normal to the cross section.

The above-described approach for the calculation of ice discharge is valid for grounded sections of tidewater glaciers. The analysis of the available radar profiles, together with the flotation criterion, indicates that a few of the studied glaciers have floating tongues or are close to flotation, in agreement with Williamson and others (2008). However, in all cases we have calculated the fluxes at locations where the glaciers are grounded.

\subsection{Cross-sectional profile approaches}

When airborne radar data are only available along a profile close to the glacier central flowline, the set of points to be used for approximating the cross-sectional thickness profile is limited to three points: the intersection of the longitudinal radar profile with the selected cross section and the intersection of the cross section with the glacier margins. In the two latter points, zero ice thickness is most often assumed.

We consider in our analysis three different approaches to the cross-sectional area of a tidewater glacier (Fig. 1b). The first approach is the one used by Van Wychen and others (2014, 2016), who used a parabola with axis at the glacier centreline, assuming that the radar-measured ice thickness $H_{\mathrm{m}}$ corresponds to the glacier centreline (Fig. 2 with $H_{\mathrm{m}}=H_{\mathrm{c}}$ ) and that the ice thickness at both margins, $x= \pm W$, is of $10 \mathrm{~m}$; for short, we will refer to this approach as centred 


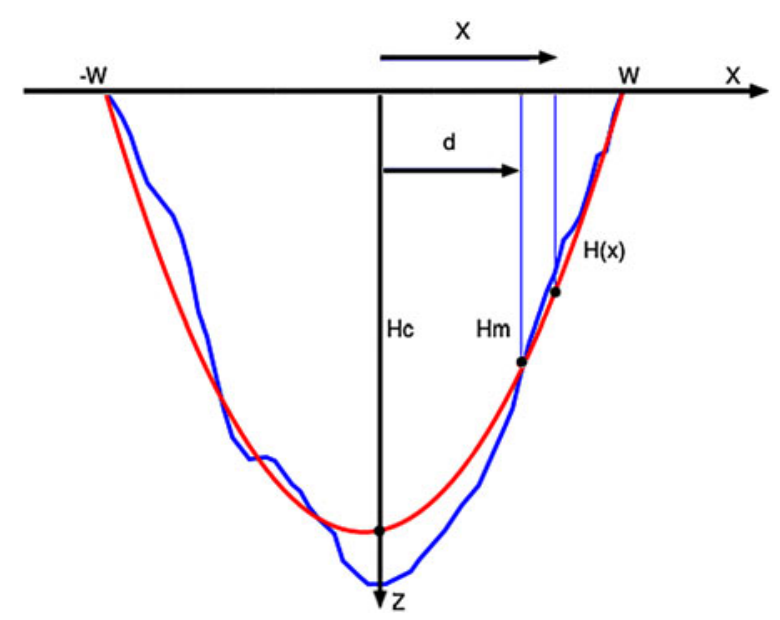

Fig. 2. Geometry of the U-shaped cross-sectional approaches used in this study. The blue line represents the actual cross profile of Glacier North 3 (Fig. S3) from NASA Operation Ice-Bridge data acquired 4 May 2012, while the red line represents its U-shaped approximation. $H_{\mathrm{m}}$ is the radar-measured ice thickness and $H_{\mathrm{c}}$ is the ice thickness at the glacier centreline. $W$ is the glacier half-width.

parabolic. The ice thickness $H$ at a point situated at a distance $x$ from the glacier centreline is then given by

$$
H(x)=\frac{10-H_{\mathrm{m}}}{W^{2}} x^{2}+H_{\mathrm{m}},
$$

where we have renamed the variables and parameters used by Van Wychen and others $(2014,2016)$ as follows: $H_{\mathrm{m}}=$ $C, W=D_{1}$ and $x=D_{2}$.

The second approach, also of parabolic type and with axis located at the glacier centreline, differs in that $H_{\mathrm{m}}$ is not assigned to the centreline but is located at a distance $d$ from it (Fig. 2). This is more realistic as it represents the possibility that the radar longitudinal profile could have an offset from the glacier centreline. In this case, we have assumed zero ice thickness at the margins. For short, we will refer to this approach as off-centred parabolic. The equation considered is of the type

$$
H(x)=a x^{2}+b
$$

which, upon applying the constrain that the parabola passes through the points $(W, 0)$ (or $(-W, 0))$ and $(d, H)$, where $W$ represents the glacier half-width, becomes

$$
H(x)=\frac{H_{\mathrm{m}}}{W^{2}-d^{2}}\left(W^{2}-x^{2}\right) .
$$

When $d=0$, i.e. the radar flight line coincides with the glacier centreline, the latter equation reduces to Eqn (2), except for the addend 10 .

The third approach is similar to this second one except that the function is now a quartic polynomial of the type

$$
H(x)=a x^{4}+b,
$$

which, again, upon the constraint of passing through the points $(W, 0)$ and $(d, H)$, becomes

$$
H(x)=\frac{H_{\mathrm{m}}}{W^{4}-d^{4}}\left(W^{4}-x^{4}\right) .
$$

For short, we will refer to this approach as off-centred quartic.

\subsection{Intensity offset-tracking velocities}

We applied SAR offset tracking algorithm in GAMMA Remote Sensing software in order to produce ice-surface velocity fields in range and azimuth directions from Sentinel-1 TOPS IW SLC Level-1 image pairs (Wegmüller and others, 2016). The particularity of the procedure lies in the use of range offsets from ascending and descending passes, avoiding the use of azimuth offsets, since Sentinel- 1 data show a lower resolution in the azimuth direction. Simultaneously, we avoid the undesired ionospheric effect manifested in the data as azimuth streaks (Sánchez-Gámez and Navarro, 2017). We performed the error analysis for Ellesmere Island, focusing on the performance of the algorithm on stable ground (on ice-free areas on the western side of Prince of Wales Icefield). The area under consideration was $\sim 150 \mathrm{~km}^{2}$, involving $\sim 400$ velocity samples. The use of this novel approach allowed us to obtain an improved velocity field with a RMSE of $0.012 \mathrm{~m} \mathrm{~d}^{-1}$. Nevertheless, we decided to take a conservative error estimate of $0.021 \mathrm{~m} \mathrm{~d}^{-1}$ for the surface velocity field, resulting from one 20th of the range direction resolution as suggested by Strozzi and others (2002) and Werner and others (2005).

We used a matching window of 320 pixel $\times 64$ pixel $(1200 \mathrm{~m} \times 1280 \mathrm{~m})$ in the range and azimuth directions, respectively, with an oversampling factor of 2 for improving the tracking results. The sampling steps were of 40 pixel $\times 8$ pixel and the resolution of the final velocity map was $200 \mathrm{~m} \times 160 \mathrm{~m}$ in the range and azimuth directions. The geocoding was completed using the CDEM. We used a bicubic spline interpolation to generate the geocoded grid. The determined velocities fields were manually checked for mismatches in all glacierised areas. These artefacts were removed from the dataset. We paid special attention to those areas where ice discharge was calculated.

\subsection{Error analysis}

Two types of error estimates for ice discharge are considered in the literature. The first one uses upper and lower bounds for the input values (i.e., velocity and thickness), resulting in upper and lower bounds for the ice flux (Burgess and others, 2005; Williamson and others, 2008; Van Wychen and others, 2012). The second approach consists of estimating the statistically expected error using error propagation from the individual error components (Andersen and others, 2015; Vijay and Braun, 2017; Gardner and others, 2018), and requires that all the considered errors are independent and uncorrelated. In our analysis, we follow the latter approach.

\subsubsection{Case 1: cross-sectional profiles of ice thickness} are available

Applying error propagation to Eqn (1) we get

$$
\sigma_{\phi}=\sqrt{\sigma_{\phi_{\rho}}^{2}+\sigma_{\phi_{f}}^{2}+\sigma_{\phi_{H}}^{2}+\sigma_{\phi_{v}}^{2}+\sigma_{\phi_{\alpha}}^{2}},
$$

where the various terms represent the contribution to the error in ice discharge due to the uncertainties in density $\left(\sigma_{\phi_{\rho}}\right)$, ratio of surface to depth-averaged velocity $\left(\sigma_{\phi_{f}}\right)$, ice thickness $\left(\sigma_{\phi_{H}}\right)$, velocity modulus $\left(\sigma_{\phi_{v}}\right)$ and direction $\left(\sigma_{\phi_{\alpha}}\right)$, and each of the terms is of the form (taking $\sigma_{\phi_{H}}$ as an 
example)

$$
\sigma_{\phi_{H}}=\sqrt{\sum_{i}\left(\sigma_{H} \rho L_{i} f v_{i} \cos \alpha_{i}\right)^{2}}
$$

In Eqn (7), we have omitted a term $\sigma_{\phi_{L}}^{2}$ because the bin width $L_{i}$ is assumed to be error-free. As error estimates for the ice thickness and surface velocity we took $\sigma_{H}=10 \mathrm{~m}$ (Gogineni, 2012) and $\sigma_{v}=0.021 \mathrm{~m} \mathrm{~d}^{-1}$ (Strozzi and others, 2002; Sánchez-Gámez and Navarro, 2017). Regarding the ratio of surface to depth-averaged velocity $(f)$, it is considered in the literature that $f \in[0.8,1]$ (Cuffey and Paterson, 2010). To give a good approximation for this parameter an analysis of the driving stresses present in a glacier and its derived flow regimes would be advisable (Dowdeswell and others, 2004; Burgess and others, 2005; Van Wychen and others, 2017). However, simple observation of the glacier surface features could give a hint on the flow regime and therefore help to better constrain $f$. Normally, tidewater glacier velocity at the terminus is dominated by basal sliding which makes $f$ close to unity. Van Wychen and others (2016), who used the error-bound approach, assumed lower and upper bounds for $\mathrm{f}$ of 0.8 and 1, respectively, while Andersen and others (2015) and Vijay and Braun (2017), who used the statistical-error approach, took $f=0.93 \pm 0.05$. We have also taken the latter value and error estimate for $f$. For ice density, we took $\rho=900 \pm 17 \mathrm{~kg} \mathrm{~m}^{-3}$. Finally, for calculating $\sigma_{\alpha}$ we used a moving window encompassing 10 velocity measurements along the cross section and calculated the standard deviation (std dev.) of their orientations with respect to the normal to the cross section.

The error in ice discharge given by Eqn (7) assumes that the radar ice-thickness measurement and the velocity data are temporally coincident. This assumption is often not true. In particular, in our case study, both data acquisitions are separated by $1-5$ years, depending on the glacier, and the glaciers can be expected to have undergone an ice-thickness change during that period. We take this into account by calculating the thinning (or thickening) rate and estimating the change in flux implied by the assumption of simultaneity of airborne radar and SAR acquisitions. This amount constitutes a systematic error (a bias), which we will represent as $\epsilon_{\phi_{(\partial h / \partial t)}}$ and that should be accounted for in our discharge calculations. This factor should not be disregarded, as Van Wychen and others (2016) have pointed out substantial thinning rates in this region during 1999-2015. These rates are highly variable depending on each particular glacier, and are important even when considering short periods of time because of the pulsating behaviour of many of these glaciers (Van Wychen and others, 2016, 2017). The surface elevation change of a tidewater glacier does not always indicate icethickness change, especially near the glacier fronts where flotation can occur. As discussed earlier, some of the studied glaciers have floating tongues or are close to flotation. However, in all cases, we have calculated the fluxes at locations where the glaciers are grounded, so we can safely assume that surface elevation changes correspond to ice thickness changes.

We calculated the thinning rates as difference in surface elevation between the radar data points (Icebridge data collected within 2012-15, depending on the glacier) and the corresponding points in a suitable DEM, for which we used the ArcticDEM from WorldView satellite, available for 2012 and 2014/15. To make the computation interval of the thinning rate long enough, we used the pairs radar 2012 with DEM 2014-2015, and radar 2014/15 with DEM 2012. The thinning rates were afterwards multiplied by the time interval between radar and SAR acquisitions to obtain the $\epsilon_{\phi_{(\partial h / \partial t)}}$ correction.

But, in addition to this systematic correction, the random nature of the thickness change (some glaciers thin while others thicken, the thinning rates change with time) requires to consider an error in thickness more conservative than that given by $\sigma_{\phi_{H}}$. We do this by introducing an error $\sigma_{\phi_{A}}$, calculated as an error bound for the cross-sectional area due to the uncertainty in ice thickness. We compute the magnitude of this error as the area of a band of 10-m thickness (the value of $\sigma_{H}$ ) all along the glacier cross section. The cross-sectional area incremented (decremented) by the area of this band will give us the upper (lower) bound for the cross-sectional area. If Eqn (7) is used with $\sigma_{\phi_{H}}$, we will denote the total error in flux as $\sigma_{\phi(H-\text { based })}$; if, instead, it is calculated using $\sigma_{\phi_{A}}$, then the total error in flux will be represented as $\sigma_{\phi(A-\text { based }) \text {. }}$ Obviously, $\sigma_{\phi(A-\text { based })}>\sigma_{\phi(H-\text { based }) \text {, so } \sigma_{\phi(A-b a s e d)} \text { provides a }}$ more conservative approach to the estimate of the discharge error. The use of $\sigma_{\phi(H \text {-based })}$ is only recommended in cases where the radar and SAR acquisitions are simultaneous or very close in time; otherwise, the use of $\sigma_{\phi(A-\text { based })}$ is recommended.

\subsubsection{Case 2: only centreline profiles of ice thickness are available}

When only radar profiles along the glacier centreline are available, we are forced to make an assumption on the cross-sectional area, and its associated uncertainty will become the dominant error source in the discharge calculation. We will estimate the error in cross-sectional area by comparing, for the 23 glaciers for which a radar cross profile is available (see Table 2), the areas calculated for the known cross section with those estimated using each of the three U-shape approaches described in Section 3.2. These approaches are based on an interpolation through the points of measured ice thickness and the intersection of the cross section with the glacier margins. Since the flight lines do not follow exactly the glacier centreline, we are interested in determining the error in cross-sectional area as a function of the distance $d$ between the glacier centreline and the radar flight line. With this aim, and to be able to compute some statistics on the errors, the areas and lengths of the cross sections of all 23 glaciers are normalised to unity, and each glacier's half-width is divided into 30 bins of equal length. Then, for each of the U-shape approaches and for each of the glaciers, a cross profile is calculated passing through each measured radar data point plus the two points at the glacier margins (Fig. 2), and the areas of the resulting U-shape profiles are calculated. Their differences with the corresponding known cross-sectional areas are taken as errors in cross-sectional area. Then, for each of the 30 bins, we compute the mean and the std dev. of the errors in cross-sectional area calculated for all the radar data points in the bin and for all 23 glaciers. The calculated mean represents the bias of the estimated cross-sectional area, and the calculated standard error (SE) will be taken as an error estimate of the cross-sectional area for the distance $d$ under consideration (distance from the central point of the bin to the glacier centreline). Thus, the described procedure provides a bias and an error estimate for the cross- 
Table 2. Ice discharge using observed radar cross-sectional profiles

\begin{tabular}{|c|c|c|c|c|c|c|c|c|c|c|c|c|}
\hline \multirow[b]{2}{*}{ Glacier } & \multirow[b]{2}{*}{ Latitude } & \multirow[b]{2}{*}{ Longitude } & \multicolumn{8}{|c|}{$\begin{array}{l}\text { Estimated error contributions } \\
\qquad \mathrm{Mt} \mathrm{a}^{-1}\end{array}$} & \multicolumn{2}{|c|}{$\begin{array}{l}\text { Discharge } \\
\mathrm{Mt} \mathrm{a}^{-1}\end{array}$} \\
\hline & & & $\sigma_{\phi_{f}}$ & $\sigma_{\phi_{\rho}}$ & $\sigma_{\phi_{H}}$ & $\sigma_{\phi A}$ & $\sigma_{\phi_{v}}$ & $\sigma_{\phi(H-\text { based })}$ & $\sigma_{\phi(A-\text { based })}$ & $\epsilon_{\phi_{(\partial h / \partial t)}}$ & 2016 & 2017 \\
\hline \multicolumn{13}{|c|}{ Prince of Wales Icefield } \\
\hline North 1 & 78.94 & -78.05 & 0.08 & 0.03 & 0.05 & 0.4 & 0.3 & 0.3 & 0.5 & -1 & - & 14 \\
\hline North 2 & 78.85 & -78.24 & 0.07 & 0.02 & 0.05 & 0.4 & 0.2 & 0.2 & 0.4 & -3 & 18 & 12 \\
\hline Stygge & 78.77 & -78.24 & 0.04 & 0.02 & 0.1 & 0.7 & 2 & 2 & 2.1 & -6 & 8 & 8 \\
\hline Leffert & 78.69 & -74.92 & 0.05 & 0.02 & 0.1 & 0.9 & 0.2 & 0.2 & 0.9 & -8 & 17 & 12 \\
\hline Ekblaw & 78.51 & -76.71 & 1.4 & 0.5 & 0.8 & 2.6 & 2.8 & 3.3 & 4.1 & +1 & - & 112 \\
\hline Tanquary & 78.46 & -76.08 & 0.09 & 0.03 & 0.07 & 0.4 & 0.3 & 0.3 & 0.5 & -2 & 15 & 12 \\
\hline Cadogan & 78.23 & -76.94 & 0.13 & 0.05 & 0.17 & 1.7 & 0.7 & 0.7 & 1.9 & -2 & 49 & 32 \\
\hline Trinity & 77.97 & -78.57 & 3 & 1 & 3 & 40 & 6.5 & 7.8 & 41 & -6 & 1073 & 967 \\
\hline Wykeham & 77.89 & -78.61 & 1.6 & 0.6 & 1.6 & 20 & 6.8 & 7.2 & 21 & -4 & 493 & 419 \\
\hline South Margin & 77.71 & -77.88 & 0.1 & 0.04 & 0.2 & 4.7 & 11 & 11 & 12 & -6 & 67 & 53 \\
\hline \multicolumn{13}{|c|}{ Devon Ice Cap } \\
\hline Sverdrup & 75.72 & -83.18 & 0.08 & 0.03 & 0.1 & $0.6^{\circ}$ & 0.4 & 0.4 & 0.7 & -1 & 12 & 7 \\
\hline Eastern & 75.79 & -82.00 & 0.2 & 0.08 & 0.3 & 1.4 & 0.3 & 0.5 & 1.5 & +1 & 27 & 21 \\
\hline Belcher & 75.67 & -81.39 & 1.1 & 0.4 & 1.2 & 7.3 & 4 & 4.3 & 8.4 & -6 & 176 & 174 \\
\hline Fitzroy & 75.45 & -80.46 & 0.4 & 0.2 & 0.5 & 3.5 & 1.1 & 1.3 & 3.6 & +2 & 84 & 75 \\
\hline East & 75.07 & -80.41 & 0.1 & 0.03 & 0.2 & 1.3 & 0.3 & 0.4 & 1.3 & +8 & 17 & 9 \\
\hline South East 1-2 & 74.98 & -80.44 & 0.2 & 0.07 & 0.2 & 1.4 & 1.2 & 1.2 & 1.8 & -6 & 34 & 64 \\
\hline South Crocker & 74.85 & -83.20 & 0.2 & 0.08 & 0.3 & 1.7 & 0.4 & 0.5 & 1.8 & 0 & 31 & 47 \\
\hline North Crocker & 74.91 & -83.62 & 0.03 & 0.01 & 0.05 & 0.5 & 0.3 & 0.3 & 0.6 & -3 & 6 & 8 \\
\hline \multicolumn{13}{|c|}{ Northern Ellesmere Icefield } \\
\hline Marine & 82.24 & -81.74 & 0.01 & 0 & 0.02 & 0.1 & 0.2 & 0.2 & 0.2 & -4 & 2 & 2 \\
\hline Marine North & 82.41 & -82.56 & 0.02 & 0.01 & 0.03 & 0.2 & 0.2 & 0.2 & 0.3 & -3 & 6 & 6 \\
\hline \multicolumn{13}{|c|}{ Manson Icefield } \\
\hline Mittie West Arm & 76.90 & -79.53 & 0.02 & 0.01 & 0.02 & 0.1 & 0.4 & 0.4 & 0.4 & 0 & 4 & 6 \\
\hline Mittie East Arm & 76.87 & -79.12 & 0.02 & 0.01 & 0.02 & 0.2 & 0.5 & 0.5 & 0.5 & 0 & 6 & 5 \\
\hline \multicolumn{13}{|c|}{ Sydkap Ice Cap } \\
\hline Sydkap & 76.62 & -85.11 & 0.2 & 0.08 & 0.3 & 1.4 & 2.4 & 2.4 & 2.8 & +5 & 29 & 23 \\
\hline
\end{tabular}

sectional area as a function of the distance $d$ between the radar flight line and the glacier centreline, as shown in Figure 3 (we assume that the errors are equal at corresponding distances at each side of the centreline).

\section{RESULTS AND DISCUSSION}

\subsection{Computed ice discharge and estimated errors for glaciers with radar cross-sectional profiles}

Table 2 shows the discharge results obtained, for the winters of 2016 and 2017, for all glaciers with available cross-sectional radar profiles, together with their corresponding error estimates and the detail of the various error components. The discharge values are given in $\mathrm{Mt} \mathrm{a}^{-1}$, and thus correspond to the extrapolation of winter estimates (typically, end of January to mid-March) to annual values. The annual values should not differ much from those given here, as the end-of-winter glacier velocities in the Canadian High Arctic are very close to their annual averages (e.g. 13.6\% lower for Ellesmere and Axel Heiberg glaciers (Van Wychen and others, 2016)), and the seasonal variability is typically not large (e.g. within 10-20\% for Devon glaciers (Van Wychen and others, 2012)). Moreover, the discharge values given by e.g. Van Wychen and others (2016) and Millan and others (2017) also correspond to approximately the same period in the year, which makes the comparison of results simpler.

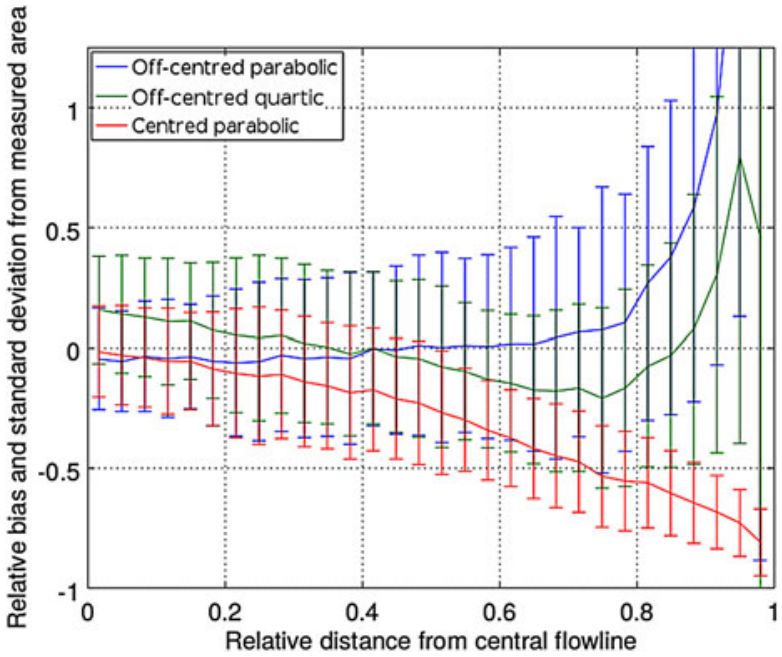

Fig. 3. Normalised cross-sectional area errors for the three different U-shape approaches, as a function of the normalised distance between the radar flight line and the glacier centreline. The vertical bars represent the std dev., and the distance from the centre of each bar to the zero line represents the corresponding bias. The continuous lines indicate the variation of the bias with the normalised distance. The blue bars/lines correspond to the offcentred parabolic approach, the green ones to the off-centred quartic approach, and the red ones to the centred parabolic approach of Van Wychen and others (2014). 
We note that the estimated error in discharge due to the errors in the angle between the velocity vector and the vector normal to the cross section, $\sigma_{\phi_{\alpha}}$, was negligible as compared with the rest of error components and therefore it has been excluded from the table. Discharge values for North 1 and Ekblaw Glaciers in 2016 are not given because of unavailability of proper SAR data.

As described in the 'Methods' section, we give two different estimates of the total error in ice discharge: $\sigma_{\phi(H-\text { based })}$, to be used in the case of temporarily coincident radar measurements and SAR acquisitions, and a more conservative error estimate $\sigma_{\phi(A-\text { based), to be used otherwise. For some glaciers, }}$ this distinction does not imply a significant difference in the error estimates. However, in other cases $\sigma_{\phi(A-\text { based })}$ is up to

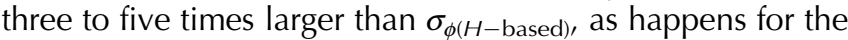
largest glaciers (Wykeham and Trinity). It is also three times larger for some medium-size glaciers (Fitzroy, South Crocker, Eastern) and three to five times larger for some small-size glaciers (East, Leffert). On average, $\sigma_{\phi(H \text {-based) }}$ is $5 \%$ of the discharge and $\sigma_{\phi(A-\text { based })}$ is $8 \%$, though individual values can be as high as 21\% (South Margin) to 25\% (Stygge) for $\sigma_{\phi(H-\text { based), }}$ and 23\% (South Margin) to 26\% (Stygge) for $\sigma_{\phi(A-\text { based }) \text {. }}$

The percentage values given under column $\epsilon_{\left.\phi_{(\partial h / \partial t}\right)}$ represent the change in discharge implied by the consideration of glacier thinning (negative values) or thickening (positive values) between the radar and SAR data acquisitions. We note that the discharge values given in the last two columns have not been corrected for this systematic error. There is a mixture of thinning and thickening glaciers, with total icethickness changes between the radar and SAR data acquisitions ranging from the $8 \%$ thinning of Leffert Glacier and the $8 \%$ thickening of East Glacier. The average of the absolute values of the ice-thickness changes is of $\sim 3 \%$. There is a clear predominance of thinning in the Prince of Wales Icefield and the Northern Ellesmere Icefield, no changes in the Manson Icefield, thickening in the Sydkap Ice Cap and no clear trend in the Devon Ice Cap.

Regarding the individual error components, as most error sources have been assigned constant values $\left(\sigma_{\rho}, \sigma_{H}, \sigma_{v}, \sigma_{f}\right)$, their individual contributions to the total error depend in a systematic way on the characteristics of each glacier (geometry, velocity field). In general, the contributions to the error in flux of the errors in $\rho$ and $f$ are small. The main contributors to the total error are the uncertainties in thickness and in velocity, as has been acknowledged by other authors (Burgess and others, 2005; McNabb and others, 2015). Their relative contributions to the total error in ice discharge will depend on the glacier under consideration, so that the thinner and slower the glaciers, the larger the shares of thickness and velocity to the total error, and conversely. The above is true when considering the total error as given by $\sigma_{\phi(H-\text { based }) \text {. }}$ If, instead, we use $\sigma_{\phi(A-\text {-based) }}$ as total error estimate then the interpretation on how the glacier characteristics affect the error estimate changes. In this case, the velocity field is the largest contributor to the total error for most of the small glaciers (discharge $<100 \mathrm{Mt} \mathrm{a}^{-1}$ ) with low velocities $\left(<100 \mathrm{~m} \mathrm{a}^{-1}\right)$ (Stygge, Marine, Mittie West Arm, Mittie East Arm) and some medium-size glaciers with low velocities (South Margin, Sydkap). This situation gradually changes with the glacier dimensions, so the crosssectional area uncertainty becomes the largest contributor to the total error for the largest glaciers (Trinity, Wykeham).

\subsection{Computed ice discharge and estimated errors for glaciers with radar centreline profiles}

\author{
4.2.1. Error estimates for the various U-shaped \\ approaches
}

The bias and the std dev. of the cross-sectional area calculated using each of the U-shape approaches discussed in Section 3.2 are shown, as a function of the distance $d$ between the radar flight line and the glacier centreline, in Figure 3. The bias and SE are calculated as described under case 2 of Section 3.4.

For coincident radar profile and glacier centreline, the centred parabolic approach of Van Wychen and others (2014) shows zero offset and around 20\% SE in area, and the offset steadily decreases with increasing distance radar profile-glacier centreline, without significant increase in SE. By contrast, the off-centred parabolic approach shows nearly zero offset for distances between the radar profile and the glacier centreline up to $\sim 65 \%$ of the glacier halfwidth, but then it increases exponentially. The per cent SE in this case increases steadily from values close to $20 \%$ for distances radar-centreline close to zero to about $50 \%$ for the mentioned distance of $\sim 65 \%$ of the glacier half-width. Finally, the off-centred quartic approach starts with a similar std dev. but with a rather large positive offset for distances radar-centreline close to zero. This offset decreases steadily until a distance of about $75 \%$ of the glacier halfwidth (during its decrease, it becomes negative at distances of about $40 \%$ of the glacier half-width). Then it starts to increase exponentially, although more slowly than the offcentred parabolic approach. The SE of the quartic approach increases with distance more slowly than that of the offcentred parabolic approach. The exponential growth of the bias for the off-centred approaches, for large distances between the radar profile and the glacier centreline (i.e. when the radar flight line approaches the glacier margins) is a consequence of the fact that the denominator in Eqns (4) and (6) approaches zero in such cases, while no such impact is visible in Eqn (2) (note, however, that the latter equation is based on the ideal assumption that the radar flight line and the glacier centreline are coincident).

The negative offset of the centred parabolic approach is consistent with the results by Van Wychen and others (2014), who noted that their approach underestimated the cross-sectional area by $\sim 12 \%$. The assumption that the longitudinal radar profile coincides with the glacier centreline is fairly good for most of the airborne radar data of NASAs Operation IceBridge. We analysed the distances (in absolute value) between the radar flight lines and designated glacier centrelines for all of the glaciers in this region, obtaining a mean distance of $\sim 22 \%$ of the glacier half-width. For this average distance from the centreline, we see from Figure 3 that our calculated underestimation of the area for the centred parabolic approach is $\sim 10 \%$, which compares well with the results by Van Wychen and others (2014). To correct for this negative bias, Van Wychen and others (2014) increased their discharge values by $12 \%$. However, the fact that the bias steadily increases in absolute value with increasing distances radar profile-centreline suggest that, rather than applying a single correction factor for all glaciers as done by Van Wychen and others (2014), it would be advisable to apply a correction factor for the cross-sectional area in a case-by-case basis, depending on the distance profile-centreline for each particular glacier. 
Based on the fact that the distance between radar profile and glacier centreline is usually not large in this region, we decided to choose the off-centred parabolic approach for our discharge calculations, as this approach shows nearly zero offset and admissible std dev. under such conditions. In fact, the distances from the profile to the glacier centreline for which the off-centred parabolic approach starts to show an undesired behaviour (large offset and std dev.) are rarely reached in the study area (Leuschen and others, 2010).

\subsubsection{Comparison of observed and estimated cross- sectional fluxes}

To check the performance of the off-centred parabolic approach, we present in Table 3 the discharge results for some glaciers for which a cross-sectional radar profile is available, obtained using: (1) the radar-measured cross-sectional area and (2) its approximation by the off-centred parabolic approach. We remark that, for each glacier, both calculations are made at the location of the available crosssectional radar profile (i.e. without considering the criteria for optimal location of the approximated cross section described in the next section), hence the slight differences with the discharge values shown later in Table 4 for the coincident glaciers.

The relative per cent differences between observed and estimated discharges, $\Delta \phi$, show that in some cases there is an underestimation (positive $\Delta \phi$ ) and in other cases an overestimation (negative $\Delta \phi$ ) of the discharge. If we exclude North 2 Glacier, for which there is a large underestimation, the average of the absolute values of the deviations is $\sim 7 \%$. The discharge error estimates are on average six times larger when using the cross-sectional area estimated using the U-shape approach. In spite of these differences, both sets of discharge estimates have comparable values, in the sense that, for each glacier, the calculated discharges by both methods are within error bounds (even for North 2 Glacier it falls within the 95\% confidence interval or $\left.\pm 1.96 \sigma_{\phi_{\text {estim }}}\right)$. Whereas for glaciers with low-to-moderate discharge (below $100 \mathrm{Mt} \mathrm{a}^{-1}$ ) the parabolic approach shows no bias, for larger glaciers (e.g. Trinity and Wykeham) the ice discharge is underestimated using both parabolic and quartic approaches (the latter one not shown in the table).
The underestimation in the parabolic case $(\sim 10-30 \%)$ is larger than that of the quartic case $(\sim 5-15 \%)$. This stresses the need for observing the cross-sectional profiles of large glaciers in order to better constrain their estimated ice fluxes.

\subsubsection{Criteria for choice of flux-gate position}

When radar ice-thickness profiles are only available along (or close to) the glacier centreline, an important decision to take is where to locate the cross section whose area is to be approximated using the U-shape approach. It might seem obvious that it should be located as close as possible to the glacier calving front, as we aim to estimate the ice discharge to the ocean. However, in this section we will see that other factors should be taken into consideration when choosing the flux-gate location. We will illustrate these criteria using the sample case of Vanier Glacier shown in Figure 4. In this figure, we show the radar flight line (panel a) and the location of four glacier cross-sections (A to D), and in panel (b), we show the variations along the radar profile of the main parameters whose values will be of help to determine a suitable location for the flux gate. These include the ice discharge, the cross-sectional area, the distance between the radar profile and the glacier centreline (expressed in the figure as position of the radar profile with respect to the glacier margins), the west-east and south-north components of the velocity field and the along-flow changes of these velocity components (i.e., the components of the velocity gradient along the radar profile); all of them are shown in panel(b).

We see in Figure $4 \mathrm{~b}$ that the ice discharge steadily decreases as we approach the glacier terminus. This is mostly due to the fact that this calculation of ice discharge does not include a correction for surface mass balance between the chosen flux gate and the glacier calving front (Gardner and others, 2011), and illustrates the importance of such a correction for flux gates distant from the glacier terminus. It is also obvious that the chosen flux gate should be closer to the terminus than the confluence of any significant tributary glacier (e.g. cross section D would not be suitable, while $\mathrm{C}$ would be admissible, because a tributary glacier coming from the northeast joins the main trunk slightly upglacier from cross section $\mathrm{C}$ ). As shown in the previous section (illustrated by Fig. 3), the choice of a cross section for

Table 3. Comparison of ice discharges calculated using observed and estimated cross-sectional profiles.

\begin{tabular}{|c|c|c|c|c|c|c|c|}
\hline \multirow[b]{3}{*}{ Glacier } & \multirow[b]{3}{*}{ Latitude } & \multirow[b]{3}{*}{ Longitude } & \multicolumn{2}{|c|}{$\begin{array}{c}\text { Discharge using observed } \\
\text { thickness data } \\
\mathrm{Mt} \mathrm{a}^{-1}\end{array}$} & \multicolumn{3}{|c|}{$\begin{array}{c}\text { Discharge using estimated } \\
\text { thickness data } \\
\mathrm{Mt} \mathrm{a}^{-1}\end{array}$} \\
\hline & & & \multicolumn{2}{|c|}{2017} & \multicolumn{3}{|c|}{2017} \\
\hline & & & $\phi_{\mathrm{obs}}$ & $\sigma_{\phi_{\mathrm{obs}}}$ & $\phi_{\text {estim }}$ & $\sigma_{\phi_{\text {estim }}}$ & $\begin{array}{c}\Delta \phi \\
\%\end{array}$ \\
\hline North 1 & 78.94 & -78.05 & 14 & 0.5 & 15 & 5.6 & -7 \\
\hline North 2 & 78.85 & -78.24 & 12 & 0.4 & 20 & 5 & -67 \\
\hline Ekblaw & 78.51 & -76.71 & 112 & 4 & 107 & 20 & 4 \\
\hline Trinity & 77.97 & -78.57 & 967 & 41 & 928 & 160 & 4 \\
\hline Wykeham & 77.89 & -78.61 & 419 & 21 & 380 & 106 & 9 \\
\hline Cadogan & 78.23 & -76.94 & 32 & 1.9 & 30 & 11 & 6 \\
\hline Sverdrup & 75.72 & -83.18 & 7 & 0.7 & 8 & 1.1 & -14 \\
\hline South East 1 & 74.98 & -80.44 & 62 & 1.8 & 63 & 12 & -2 \\
\hline South Crocker & 74.85 & -83.20 & 47 & 1.7 & 42 & 8.5 & 11 \\
\hline
\end{tabular}


Table 4. Ice discharge values calculated using estimated cross-sectional areas by means of the off-centred parabolic approach.

\begin{tabular}{|c|c|c|c|c|c|c|}
\hline \multirow[b]{2}{*}{ Glacier } & \multirow[b]{2}{*}{ Latitude } & \multirow[b]{2}{*}{ Longitude } & \multicolumn{2}{|c|}{$\begin{array}{l}\text { Estimated errors } \\
\qquad \mathrm{Mt} \mathrm{a}^{-1}\end{array}$} & \multicolumn{2}{|c|}{$\begin{array}{l}\text { Discharge } \\
\mathrm{Mt} \mathrm{a}^{-1}\end{array}$} \\
\hline & & & $\sigma_{\phi(A-\text { based })}$ & $\sigma_{\phi_{\text {avg }}}$ & 2016 & 2017 \\
\hline \multicolumn{7}{|c|}{ Prince of Wales Icefield } \\
\hline *North 1 & 78.94 & -78.05 & 5.6 & 1.8 & 10 & 3 \\
\hline *North 2 & 78.85 & -78.24 & 1.5 & 0.5 & 4 & 5 \\
\hline *Ekblaw & 78.51 & -76.71 & 20 & 6.3 & 212 & 129 \\
\hline South & 77.33 & -79.59 & 2.8 & 0.9 & 32 & 28 \\
\hline Palisade & 77.39 & -80.99 & 2.5 & 0.8 & 7 & 6 \\
\hline \multicolumn{7}{|c|}{ Northern Ellesmere Icefield } \\
\hline Disraeli North & 82.84 & -70.79 & 1.3 & 0.4 & 6 & 5 \\
\hline Disraeli & 82.67 & -72.50 & 13 & 4.1 & - & 10 \\
\hline $\mathrm{M}^{\prime}$ Clintock & 82.43 & -76.15 & 4 & 1.3 & 1 & 3 \\
\hline Milne & 82.44 & -80.22 & 6.9 & 2.2 & 30 & 45 \\
\hline Vanier & 82.14 & -80.75 & 2 & 0.6 & 4 & 8 \\
\hline DeVries & 82.01 & -79.60 & 0.4 & 0.1 & 1 & 1 \\
\hline Yelverton & 81.84 & -79.43 & 10 & 3.1 & 74 & 79 \\
\hline Otto & 81.30 & -84.70 & 0.4 & 0.1 & 1 & 0 \\
\hline \multicolumn{7}{|c|}{ Agassiz Ice Cap } \\
\hline Tuborg & 80.89 & -76.14 & 8.7 & 2.7 & 30 & 33 \\
\hline Antoinette & 80.81 & -76.30 & 4 & 1.3 & 2 & 20 \\
\hline $\mathrm{d}^{\prime}$ Iberville & 80.56 & -77.92 & 1.3 & 0.4 & 5 & 5 \\
\hline Cañon & 79.68 & -79.64 & 14 & 4.4 & 68 & 80 \\
\hline Sawyer Bay & 79.36 & -78.05 & 0.6 & 0.2 & 3 & 2 \\
\hline Parrish & 79.57 & -77.18 & 0.3 & 0.1 & 2 & 1 \\
\hline Eugenie & 79.82 & -74.93 & 4 & 1.3 & 2 & 21 \\
\hline Unnamed 4 & 80.07 & -72.39 & 2.6 & 0.8 & 10 & 10 \\
\hline \multicolumn{7}{|c|}{ Müller and Steacie Ice Caps } \\
\hline Iceberg & 79.43 & -92.37 & 1.4 & 0.4 & 9 & 8 \\
\hline Good Friday Bay & 78.55 & -91.76 & 20 & 6.3 & 9 & 11 \\
\hline
\end{tabular}

* The glaciers marked with an asterisk have an available radar cross section.

which the radar profile and the glacier centreline are close to each other is critical to prevent both an undesirable large std dev. and large bias in the estimated cross-sectional area. In particular, in the case of the off-centred parabolic approach, using any cross section for which the distance from the profile to the glacier centreline is $>65 \%$ for the glacier half-width would render the calculated ice discharges useless.

It is equally important, when choosing the flux-gate location, to avoid zones with large variations of either the crosssectional area or the glacier velocity. This is because these rapid spatial variations often correspond to marked shortscale heterogeneities of the glacier bedrock (e.g. bedrock bumps) which imply locally anomalous cross-sectional areas, as well as noise in the velocity field signal, both of which should be avoided whenever possible to minimise the error in the discharge estimate. These undesired effects can also be minimised by averaging the ice discharges calculated for several closely spaced flux gates:

$$
\begin{array}{r}
\phi_{\mathrm{avg}}=\frac{\sum_{j=1}^{n} \phi_{A-\text { based }_{j}}}{n}, \\
\sigma_{\phi_{\text {avg }}}=\frac{\sigma_{\phi(A-\text { based })}}{\sqrt{n}},
\end{array}
$$

where $n$ is the number of considered flux gates. We see in Eqn (9) that the error decreases with the inverse of the square root of $n$. We suggest a limit of 11 flux gates (ca. $150 \mathrm{~m}$ in our case study) for the averaging (the calculated discharge value would be assigned to the central flux gate), given the underlying assumption of Eqn (9) that we are averaging distinct measurements of the same quantity so the fluxes should not differ significantly. The area of each cross section would be calculated using the off-centred parabolic approach based on a different radar ice-thickness point for each cross section.

Summarising the above, our choice for the flux-gate location should be guided by:

(1) Flux gate close to the glacier terminus and downglacier with respect to any significant tributary glacier.

(2) Radar profile close to the glacier centreline.

(3) Spatial stability of the cross-sectional area calculated with the U-shaped approach.

(4) Spatial stability of the ice surface velocity field.

In Table 4 we show the ice discharges calculated using the off-centred parabolic approach for glaciers with only one radar longitudinal profile, close to the glacier centreline (no cross-sectional profiles available). The location of the approximated cross section has been selected following the criteria discussed above. The $U$-shape approximation has also been applied to three glaciers (marked with an asterisk) for which there is an available cross-sectional radar profile. The reason is that, for these glaciers, the available radar cross section is located far from the calving front (especially for North 1 and North 2). This implies a large difference between the discharge estimates calculated using the observed cross section (in Table 2 and in column $\phi_{\text {obs }}$ of Table 3) and the estimated discharge shown in Table 4, which is based on an estimated cross section situated 


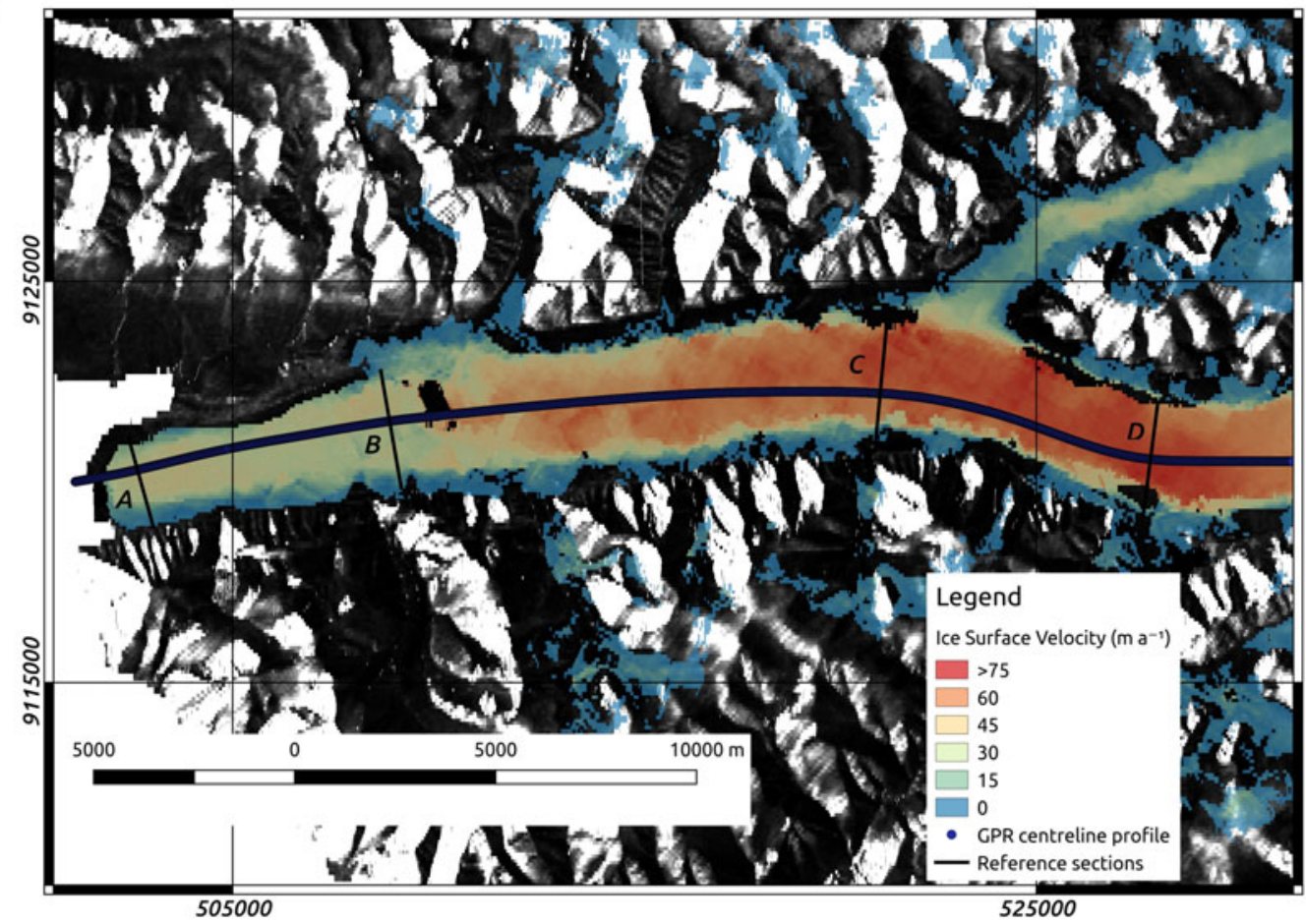

b

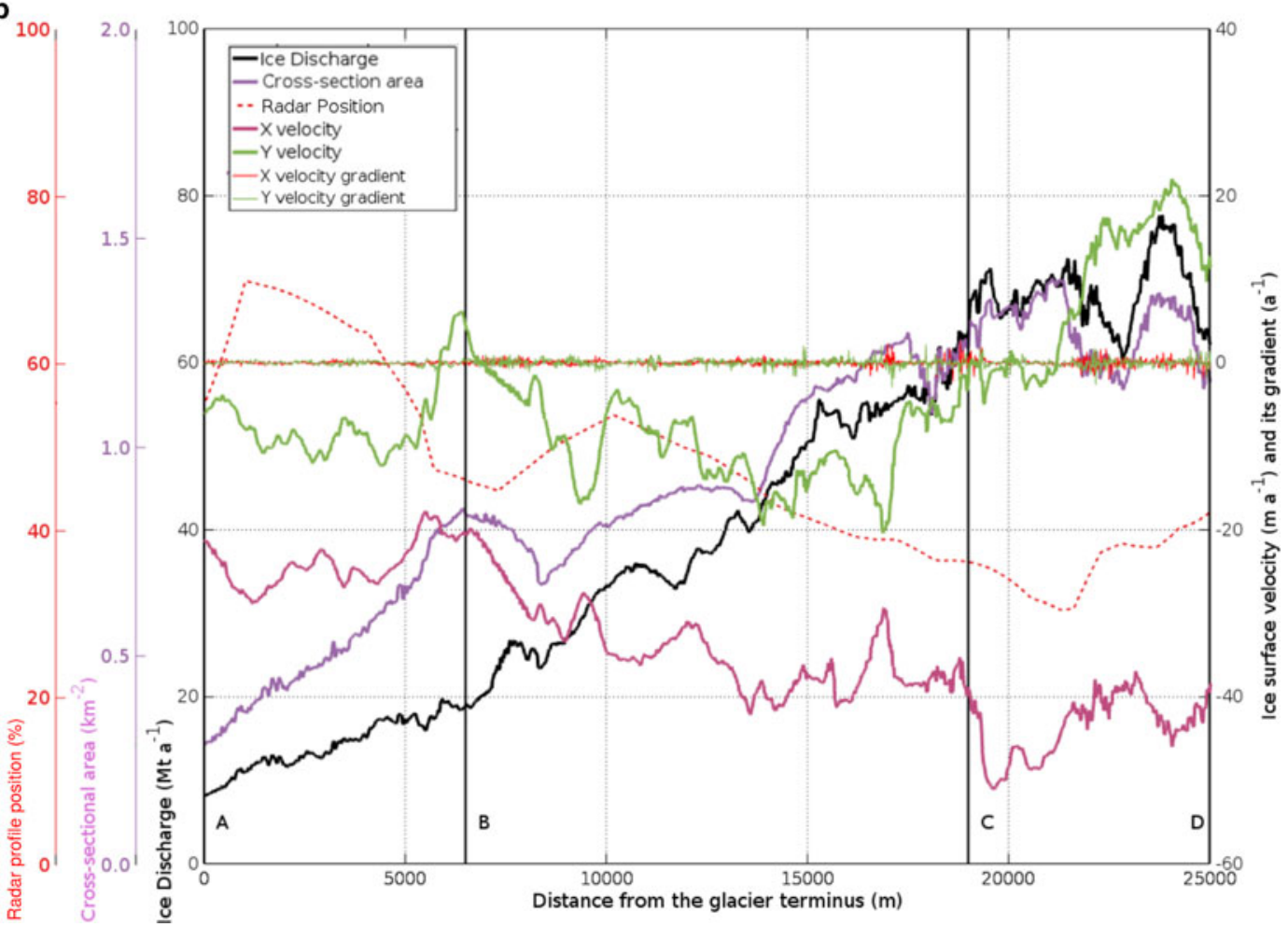

Fig. 4. Spatial variations along the radar longitudinal profile of Vanier Glacier of the main parameters to be considered for a suitable choice of the flux-gate location. In panel (b), the relative position of the radar profile is indicated (lefts axis) as the percentage over the total glacier crosssectional length; therefore a $50 \%$ value indicates that the radar profile is located exactly at the glacier centreline.

much closer to the glacier terminus. Consequently, the latter does not need a correction for surface mass balance between the flux-gate position and the calving front, while the former would require it to provide a fair estimate of the ice discharge to the ocean. Therefore, the estimate of ice discharge given in Table 4 for these particular glaciers is the recommended one. As shown in Table 4, errors are reduced when averaging the ice discharge using several closely spaced flux gates as described in Eqn (9) (compare $\sigma_{\phi(A-\text { based })}$ with $\left.\sigma_{\phi_{\text {avg }}}\right)$.

\subsection{Comparison of calculated ice discharge with other studies}

Several recent studies have dealt with the estimation of ice discharge from tidewater glaciers of the Canadian High 
Arctic (Van Wychen and others, 2016, 2017; Millan and others, 2017) and a further study has analysed the glacier surface velocity changes in the circum-Arctic region (Strozzi and others, 2017). We compare their results with those presented in this paper with the support of Table 5. We note that the measurements from all studies correspond to approximately the same period of the year, the end of the winter, so differences should not be attributed to seasonality. We see that, in most cases, their results are comparable and consistent with those presented here.

When comparing our results with those of Van Wychen and others (2016), we acknowledge an increase of ice discharge from the main glaciers of the Prince of Wales Icefield (Trinity and Wykeham) in 2016, in line with the trend indicated by Van Wychen and others (2016) for 2013-15. This increase is followed by a decrease in 2017, which is consistent with the decrease in surface velocities of the main Canadian Arctic tidewater glaciers pointed out by Strozzi and others (2017). In fact, the only large tidewater glacier keeping a similar rate of ice discharge for both 2016 and 2017 is Belcher Glacier in Devon Ice Cap. However, the mentioned increase in discharge for Trinity and Wykeham from 2015 to 2016 becomes a substantial decrease (also for Belcher) if we compare our results with those of Millan and others (2017). If the comparison of our results were limited to those obtained by the latter authors for 2015, we could think that the differences in discharge estimates for Trinity, Wykeham and Belcher, 27, 28 and 20\% lower (respectively) for 2016 in our estimate, could be partly attributed to interannual variations in ice discharge, even if these show typical values of $\sim 10-15 \%$ for Canadian High Arctic glaciers, obtained from comparison of differential GPS data recorded during the summer and winter months (Van Wychen and others, 2014). However, we note that there is an inconsistency between the estimates by Van Wychen and others $(2016,2017)$ and by Millan and others (2017) for 2015, with discharge estimates by the latter authors substantially higher for the largest glaciers, by 27, 29 and 29\% for Trinity, Wykeham and Belcher, respectively. In all three cases, our own estimates for 2016 are much closer to those given by Van Wychen and others $(2016,2017)$.

Comparing our results with those of Van Wychen and others $(2016,2017)$ and Millan and others (2017), we note a substantial increase in discharge of Ekblaw Glacier in 2016 , followed by a decrease in 2017, though maintaining a level higher than that of 2015. Though our estimate for 2016 can seem very high, it is comparable with the values given for 2011-12 by Van Wychen and others (2016) (not shown in table). This is no surprise, considering the pulsating behaviour of Ekblaw Glacier noted by Van Wychen and others (2016), and are within the range of random variations during the period 1999-2015 analysed by these authors. We also found differences in ice discharge for Tanquary Glacier, whose discharges for 2016 and 2017 are lower than that observed by Van Wychen and others (2016) in 2015, but similar to that given by Millan and others (2017) also for 2015. We found that the surface velocity field of this glacier presents a singular behaviour, with its southern part showing no signs of movement. The ice flowing in this area comes from four tributary glaciers located to the south of Tanquary, which are nearly stagnant. The difference in discharge estimates could be due to a distinct weight given to the differing velocities of the northern and southern parts of the cross section, although an alternative explanation is that the glacier could be entering into a quiescent phase. For Sydkap and Cadogan Glaciers we also find a decrease in discharge in 2016, and a further decrease in 2017, from the figures reported by Van Wychen and others (2016) for 2015. The pattern is similar for Sydkap when compared with the results by Millan and others (2017), though different for Cadogan due to the $33 \%$ lower estimate by Millan and others (2017) as compared with Van Wychen and others (2016). In the Devon Ice Cap, Fitzroy Glacier shows no sign of change when compared with Van Wychen and others (2017) results, but Millan and others (2017) gave a discharge estimate $33 \%$ lower than that of Van Wychen and others (2017). We note that there is a gap in ice-thickness data for a certain area of Fitzroy Glacier, which could be the reason for at least part of the observed differences in ice discharge estimates.

The main glaciers of Aggasiz Ice Cap, Tuborg and Cañon, show similar discharge values for the present study and those for 2015 by Van Wychen and others (2016) and Millan and others (2017). For Yelverton Glacier, the main active glacier of Northern Ellesmere Icefield (Otto Glacier is in its quiescence phase), our estimate is closer to that of Van

Table 5. Comparison of ice discharge values between studies

This study

\begin{tabular}{|c|c|c|c|c|}
\hline \multirow[b]{2}{*}{ Glacier } & \multirow[b]{2}{*}{ Van Wychen and others (2016) } & \multirow[b]{2}{*}{ Millan and others (2017) } & \\
\hline & & & Using observed profiles & Using estimated profiles \\
\hline Trinity & $1.02(2015)$ & $1.30(2015)$ & 1.07 (2016) 0.97 (2017) & - \\
\hline Wykeham & $0.41(2015)$ & $0.53(2015)$ & 0.49 (2016) 0.42 (2017) & - \\
\hline Ekblaw & $0.08(2015)$ & $0.06(2015)$ & $0.11(2017)$ & $0.21(2016)$ \\
\hline Tanquary & $0.05(2015)$ & $0.01(2015)$ & 0.02 (2016) 0.01 (2017) & - \\
\hline Sydkap & $0.04(2015)$ & $0.05(2015)$ & 0.03 (2016) 0.02 (2017) & - \\
\hline Yelverton & $0.08(2015)$ & $0.11(2015)$ & - & 0.07 (2016) 0.08 (2017) \\
\hline Fitzroy & $0.08(2015)$ & $0.05(2015)$ & 0.08 (2016) 0.08 (2017) & - \\
\hline Tuborg & $0.03(2015)$ & $0.03(2015)$ & - & 0.03 (2016) 0.03 (2017) \\
\hline Cañon & $0.07(2015)$ & $0.07(2015)$ & - & 0.07 (2016) 0.08 (2017) \\
\hline Milne & $0.06(2015)$ & $0.04(2015)$ & - & 0.03 (2016) 0.05 (2017) \\
\hline Good Friday Bay & $0.05(2015)$ & $0.08(2015)$ & - & 0.01 (2016) 0.01 (2017) \\
\hline
\end{tabular}

All values are given in $\mathrm{Gt}^{-1}$. 
Wychen and others (2016), while for Milne Glacier our estimate is closer to that of Millan and others (2017). Both Glaciers, Yelverton and Milne, show a similar pattern of decrease in discharge from 2015 to 2016, followed by an increase in 2017. Good Friday Bay Glacier, located in the Steacie Ice Cap, presents a different discharge for all three studies. We believe that this disparity should not be attributed to seasonality or interannual variability, nor to its surging behaviour (Copland and others, 2003; Van Wychen and others, 2016). Rather, we attribute this difference to the location of the flux gate in our study. The terminus of this glacier advanced $\sim 2 \mathrm{~km}$ during 2000-2015 (Van Wychen and others, 2016). This advance implies an increase of the glacier area in its lowest part. Therefore, the effect of the surface mass-balance losses on the increased glacier area could easily account for the differences in estimated ice discharge. Indeed, when calculating the ice discharge using radar observations close to the terminus we obtain an ice flux of $\sim 10 \mathrm{Mta}^{-1}$, while when calculating it for flux-gates $10 \mathrm{~km}$ upglacier from the terminus (avoiding the area where a Nunatak is present), our estimated discharge value becomes similar to that of Van Wychen and others (2016).

\section{CONCLUSIONS AND OUTLOOK}

We have analysed the contributions of the various error components involved in the estimation of ice discharge through predefined flux gates, distinguishing two cases: (1) ice-thickness data are available for glacier cross sections close to the glacier terminus and (2) ice-thickness data are only available along the glacier centreline. In the latter case, we have analysed the performance of three different U-shaped cross-sectional approaches, and given hints for the choice of a suitable location of the flux gate. The following conclusions can be drawn from our study:

Regarding the relative contribution from the various error components:

(1) The velocity field is the dominant source of error for small and medium-size glaciers (discharge $<100 \mathrm{Mt} \mathrm{a}^{-1}$ with low velocities $\left(<100 \mathrm{~m} \mathrm{a}^{-1}\right)$.

(2) For large glaciers (discharge $>100 \mathrm{Mt} \mathrm{a}^{-1}$ ) with high velocities $\left(>100 \mathrm{~m} \mathrm{a}^{-1}\right)$ the error in cross-sectional area becomes the main contributor to the total error. This stresses the need of measuring radar cross-sectional profiles for the largest glaciers.

(3) The bias (systematic error) implied by glacier thinning/ thickening between the radar and SAR acquisitions is variable according to subregions, oscillating between $8 \%$ and $-8 \%$ of the discharge value over the period of 2-5 years between acquisitions, with an average of the absolute values of $\sim 3 \%$. Temporally coincident radar and SAR acquisitions are recommended to reduce the effect of the bias, especially for the largest glaciers (Trinity, Wykeham, Belcher, Ekblaw), which contribute to most of the ice discharge in the region.

Concerning the performance of the $U$-shaped cross-sectional approaches:

(1) If the radar flight line is not too far from the glacier centreline, the off-centred parabolic approach shows the lowest bias and acceptable std dev., so it is the recommended approach.
(2) The centred parabolic approach shows nearly constant std dev., but is more strongly biased than the offcentred approach for common distances flight linecentreline.

(3) The off-centred quartic approach shows large variable bias and its std dev., though nearly constant, is large.

Finally, regarding the comparison of the ice discharge results presented here for the winters of 2016 and 2017 with the results for 2015 presented by Van Wychen and others (2016, 2017) and Millan and others (2017), in general we see comparable results with only small differences. When there is a difference between the results by these authors (usually a larger estimate by Millan and others (2017)), our data in general agree better with those by Van Wychen and others (2016, 2017), so we will comment on the comparison with the latter to gain some understanding on the interannual changes. There is an increase of ice discharge from the main glaciers (Trinity and Wykeham) of the Prince of Wales Icefield from 2015 to 2016 , by 5 and $20 \%$, respectively, but this is followed by a decrease in 2017 , by 10 and $15 \%$, respectively, consistent with the reduction in surface velocities of the main Canadian Arctic tidewater glaciers pointed out by Strozzi and others (2017). Among the largest glaciers, only Belcher Glacier, in the Devon Ice Cap, maintains similar discharges during the period 2015-17. Two small glaciers show significant decreases in ice discharge. Tanquary, part of the Prince of Wales Icefield, changes by 70\% from 2015 to 2016, and a further $20 \%$ from 2016 to 2017 . Good Friday Bay, part of the Steacie Ice Cap, decreases by $80 \%$ from 2015 to 2016, remaining stable in 2017.

In our view, most of the work remaining to be done does not correspond to the analysis of error estimates of ice discharge through given flux gates and at a given time, as done in this paper, but to the approximation of the frontal ablation of tidewater glaciers by the ice discharge calculated at flux gates close to the calving front. Aside from seasonality and interannual variability considerations, we believe that two critical aspects deserve further investigation for Canadian High Arctic glaciers: (1) the surface mass balance between the flux gate location and the calving front, and (2) the front position changes. If the surface mass balance effects are ignored, the overestimate of frontal ablation is expected to be large for Canadian High Arctic glaciers, because of the strongly negative recent surface mass balance of the Canadian Arctic, with values between - 1.5 and $-2.0 \mathrm{~m}$ w.e. $\mathrm{a}^{-1}$ at the lowermost part of the tidewater glaciers during 2003-09 (Gardner and others, 2011). Our own preliminary estimates for the studied glaciers suggest typical overestimates by $\sim 30 \%$ of the calculated ice discharge, reaching up to $50 \%$ for individual glaciers. Regarding the effect of the terminus advance/retreat, it is difficult to quantify for Canadian High Arctic glaciers, due to the pulsating behaviour of many of them. As noted by Van Wychen and others (2016), pulse- and surge-type glaciers have some common characteristics, such as periods of speedup and slowdown, and terminus advance coincident with acceleration, but their key difference is that all of the velocity variability of the pulse-type glaciers appears to be restricted to their lowermost terminal region, which is grounded below sea level. Very little interannual variability is observed upglacier from this area. This poses difficulties in the approximation of frontal ablation by ice discharge 
through flux gates, as these estimates are heavily dependent on flux-gate location for the pulsating glaciers. This stresses the importance of monitoring the terminus advance/retreat for the glaciers in this region, as has been done during the last decades (Burgess and Sharp, 2004; Burgess and others, 2005; Williamson and others, 2008; Van Wychen and others, 2016).

\section{SUPPLEMENTARY MATERIAL}

The supplementary material for this article can be found at https://doi.org/10.1017/jog.2018.48.

\section{ACKNOWLEDGMENTS}

This study has received funding from the European Union's Horizon 2020 research and innovation programme under grant agreement No 727890 and from grant CTM201456473-R of the Spanish National Plan for Research and Development. It has been carried out under the frames of the Network on Arctic Glaciology of the International Arctic Science Committee (IASC-NAG). Some data used in this paper were acquired by NASA's Operation IceBridge Project. Copernicus Sentinel data 2016-17, processed by ESA. The paper was greatly improved by the comments and suggestions of two anonymous referees, the Scientific Editor Michelle Koutnik and the Associate Chief Editor Frank Pattyn.

\section{REFERENCES}

Andersen $M$ and 10 others (2015) Basin-scale partitioning of Greenland ice sheet mass balance components (2007-2011). Earth Planet. Sci. Lett, 409, 89-95. (doi: 10.1016/j.epsl.2014. 10.015)

Błaszczyk M, Jania J and Hagen J (2009) Tidewater glaciers of Svalbard: recent changes and estimates of calving fluxes. Pol. Polar Res., 30(2), 85-142.

Brown C, Meier M and Post A (1982) Calving speed of Alaska tidewater glaciers, with application to Columbia Glacier. U.S. Geol. Surv. Prof. Pap., 1258-C, C1-C13.

Burgess D and Sharp M (2004) Recent changes in areal extent of the Devon Ice Cap, Nunavut, Canada. Arct. Antarct. Alp. Res., 36(2), 261-271. (doi: 10.1657/1523-0430(2004)036[0261:rciaeo]2.0. co;2)

Burgess D, Sharp M, Mair D, Dowdeswell J and Benham T (2005) Flow dynamics and iceberg calving rates of Devon Ice Cap, Nunavut, Canada. J. Glaciol., 51(173), 219-230. (doi: 10.3189/ 172756505781829430)

Burgess E, Forster R and Larsen C (2013) Flow velocities of Alaskan glaciers. Nat. Commun., 4, 2146 (doi: 10.1038/ncomms3146)

Cogley J and others (2011) Glossary of glacier mass balance and related terms. IHP-VII Tech. Doc. in Hydrol., 86, UNESCOIHP, IACS Contribution 2, Paris, France.

Copland L, Sharp M and Dowdeswell J (2003) The distribution and flow characteristics of surge-type glaciers in the Canadian High Arctic. Ann. Glaciol., 36, 73-81. (doi: 10.3189/ 172756403781816301)

Cuffey K and Paterson W (2010) The physics of glaciers, 4th edn. Butterworth-Heinemann,Oxford.

Dowdeswell J, 10 others (2002) Form and flow of the Academy of Sciences Ice Cap, Severnaya Zemlya, Russian High Arctic. J. Geophys. Res, 107(B4), 2076 (doi: 10.1029/2000jb000129)

Dowdeswell J, Benham T, Gorman M, Burgess D and Sharp M (2004) Form and flow of the Devon Island Ice Cap, Canadian
Arctic. J. Geophys. Res., 109(F2), L02002 (doi: 10.1029/ 2003jf000095)

Dowdeswell J, Benham T, Strozzi T and Hagen J (2008) Iceberg calving flux and mass balance of the Austfonna Ice Cap on Nordaustlandet, Svalbard. J. Geophys. Res., 113 (F3) (doi: 10.1029/2007jf000905)

Farinotti D, Huss M, Bauder A, Funk M and Truffer M (2009) A method to estimate the ice volume and ice-thickness distribution of alpine glaciers. J. Glaciol., 55(191), 422-430. (doi: 10.3189/ 002214309788816759)

Gardner A and 8 others (2011) Sharply increased mass loss from glaciers and ice caps in the Canadian Arctic Archipelago. Nature, 473(7347), 357-360. (doi: 10.1038/nature10089)

Gardner AS, 6 others (2018) Increased West Antarctic and unchanged East Antarctic ice discharge over the last 7 years. The Cryosphere, 12(2), 521-547. (doi: 10.5194/tc-12-521-2018)

Geudtner D, Torres R, Snoeij P, Davidson M and Rommen B (2014) Sentinel-1 system capabilities and applications. In 2014 IEEE Geoscience and Remote Sensing Symp., IEEE (doi: 10.1109/ igarss.2014.6946711)

Gogineni P (2012) Radar Depth Sounder Data Products. Digital media, Lawrence, Kansas.

Harbor J (1992) Numerical modeling of the development of U-shaped valleys by glacial erosion. Geol. Soc. Am. Bull., 104 (10), 1364-1375. (doi: 10.1130/0016-7606(1992)104¡1364: nmotdo 2 2.3.co;2)

Holzner J and Bamler R (2002) Burst-mode and ScanSAR interferometry. IEEE Trans. Geosci. Remote Sens., 40(9), 1917-1934. (doi: 10.1109/tgrs.2002.803848)

Leuschen C, Gogineni P, Rodriguez-Morales F, Paden J and Allen C (2010) Icebridge MCoRDS L2 Ice Thickness, Version 1 (doi: 10.5067/GDQ0CUCVTE2Q)

McNabb R, Hock R and Huss M (2015) Variations in Alaska tidewater glacier frontal ablation, 1985-2013. J. Geophys. Res., 120(1), 120-136. (doi: 10.1002/2014jf003276)

Millan R, Mouginot J and Rignot E (2017) Mass budget of the glaciers and ice caps of the Queen Elizabeth Islands, Canada, from 1991 to 2015. Environ. Res. Lett., 12(2), 024016 (doi: 10.1088/17489326/aa5b04)

NRCAN (2016) Canadian Digital Elevation Model Product Specifications. Government of Canada, Sherbrooke, Quebec, Canada, 1.1 edition.

Osmanoğlu B, Braun M, Hock R and Navarro F (2013) Surface velocity and ice discharge of the ice cap on King George Island, Antarctica. Ann. Glaciol., 54(63), 111-119. (doi: 10.3189/ 2013aog63a517)

Osmanoğlu B, Navarro F, Hock R, Braun M and Corcuera M (2014) Surface velocity and mass balance of Livingston Island ice cap, Antarctica. The Cryosphere, 8(5), 1807-1823. (doi: 10.5194/tc8-1807-2014)

Pfeffer W and 18 others (2014) The Randolph Glacier Inventory: a globally complete inventory of glaciers. J. Glaciol., $60(221)$, 537-552. (doi: 10.3189/2014JoG13J176)

Radić V and Hock R (2010) Regional and global volumes of glaciers derived from statistical upscaling of glacier inventory data. J. Geophys. Res., 115(F1), F01010 (doi: 10.1029/2009jf001373)

Rignot E, Box J, Burgess E and Hanna E (2008) Mass balance of the Greenland ice sheet from 1958 to 2007. Geophys. Res. Lett., 35 (20), L20502 (doi: 10.1029/2008gl035417)

Sánchez-Gámez P and Navarro F (2017) Glacier surface velocity retrieval using $d$-InSAR and offset tracking techniques applied to ascending and descending passes of Sentinel-1 Data for Southern Ellesmere Ice Caps, Canadian Arctic. Remote Sens., 9 (5), 442 (doi: 10.3390/rs9050442)

Sharp M and 12 others (2014) Remote sensing of recent glacier changes in the Canadian Arctic. InKargel J, Leonard G, Bishop M, Kääb A and Raup B (eds.), Global and ce easurements from pace, Praxis, Springer, chapter 9, 205-228.

Strozzi T, Luckman A, Murray T, Wegmuller U and Werner C (2002) Glacier motion estimation using SAR offset-tracking procedures. 
IEEE Trans. Geosci. Remote Sens., 40(11), 2384-2391. (doi: 10.1109/tgrs.2002.805079)

Strozzi T, Paul F, Wiesmann A, Schellenberger T and Kääb A (2017) Circum-Arctic changes in the flow of glaciers and ice caps from satellite SAR data between the 1990s and 2017. Remote Sens., 9 (9), 947 (doi: 10.3390/rs9090947)

Thomas R, 6 others (2000) Mass balance of the Greenland Ice Sheet at High elevations. Science, 289(5478), 426-428. (doi: 10.1126/ science.289.5478.426)

Van Wychen W and 5 others (2012) Spatial and temporal variation of ice motion and ice flux from Devon Ice Cap, Nunavut, Canada. J. Glaciol., 58(210), 657-664. (doi: 10.3189/2012jog11j164)

Van Wychen W and 6 others (2014) Glacier velocities and dynamic ice discharge from the Queen Elizabeth Islands, Nunavut, Canada. Geophys. Res. Lett., 41(2), 484-490. (doi: 10.1002/ 2013gl058558)

Van Wychen W and 5 others (2015) Glacier velocities and dynamic discharge from the ice masses of Baffin Island and Bylot Island, Nunavut, Canada. Can. J. Earth Sci., 52(11), 980-989. (doi: 10.1139/cjes-2015-0087)

Van Wychen W and 6 others (2016) Characterizing interannual variability of glacier dynamics and dynamic discharge (1999-2015) for the ice masses of Ellesmere and Axel Heiberg Islands,
Nunavut, Canada. J. Geophys. Res., 121(1), 39-63. (doi: 10. 1002/2015jf003708)

Van Wychen W and 7 others (2017) Variability in ice motion and dynamic discharge from Devon Ice Cap, Nunavut, Canada. J. Glaciol., 63(239), 436-449. (doi: 10.1017/jog.2017.2)

Vijay S and Braun M (2017) Seasonal and interannual variability of Columbia Glacier, Alaska (2011-2016): Ice velocity, mass flux, surface elevation and front position. Remote Sens., 9(7), 635 (doi: 10.3390/rs9060635)

Wegmüller $U$ and 5 others (2016) Sentinel-1 support in the GAMMA software. Procedia. Comput. Sci., 100, 1305-1312. (doi: 10.1016/j.procs.2016.09.246)

Werner C, Wegmüller U, Strozzi T and Wiesmann A (2005) Precision estimation of local offsets between pairs of SAR SLCs and detected SAR images. IGARSS'05, Seoul, Korea, 25-29 July 2005, 4803-4805.

Wessel P and Smith W (1996) A global, self-consistent, hierarchical, high-resolution shoreline database. J. Geophys. Res., 101(B4), 8741-8743. (doi: 10.1029/96JB00104)

Williamson S, Sharp M, Dowdeswell J and Benham T (2008) Iceberg calving rates from northern Ellesmere Island ice caps, Canadian Arctic, 1999-2003. J. Glaciol., 54(186), 391-400. (doi: 10. 3189/002214308785837048)

MS received 7 February 2018 and accepted in revised form 9 May 2018; first published online 14 June 2018 